\title{
An Experimental and Numerical Investigation of an Improved Shearing Process with Different Punch Characteristics
}

\author{
Mahmod Gomah ${ }^{1}$ - Murat Demiral2,1,* \\ ${ }^{1}$ Mechanical Engineering Department, University of Turkish Aeronautical Association, Turkey \\ ${ }^{2}$ College of Engineering and Technology, American University of the Middle East, Kuwait
}

Blanking and piercing shearing processes have been widely used to manufacture workpieces for industrial, commercial and testing purposes. During the operation, the punch is exposed to higher stresses and, due to the cycled contact of opposite surfaces, it can be worn significantly. As its surface directly affects the quality of sheet products and causes some surface defects, its performance plays a significant role. In this study, various tools with different characteristics were investigated for an improved shearing process. First, a novel punch with a hemispherical ball at the centre of its flat face was tested and compared with a conventional one. The process was simulated using ABAQUS/Explicit finite element (FE) program, in which the Johnson-Cook material model with its complementary damage model was used to represent the behaviour of the sheet material. Based on this, an optimum geometry for the proposed punch was determined. Secondly, the wear resistance of TiN, CrN, TiSiN, AlCrN and AlTiN coated punches, produced with physical vapour deposition (PVD) technique, and of the polycrystalline diamond compact (PDC) cutter were compared based on scanning electron microscope (SEM) micrographs after 1000 strokes under dry cutting conditions.

Keywords: punch geometry, wear, physical vapour deposition coating, polycrystalline diamond compact cutters

\section{Highlights}

- A novel punch with a hemispherical ball at the centre of its flat face was proposed; better performance compared to the conventional punch was achieved.

- $\quad$ Based on the simulations, $2.4 \mathrm{~mm}$ was found to be the optimum radius of the hemispherical part of the punch.

- Wear on the surfaces of TiN, CrN, TiSiN, AICrN and AlTiN coated punches based on 1000 strokes were compared: the last two of them showed the best performances.

- $\quad$ The wear performance of the PDC cutter showed that it could be an alternative against the coated punches in the shearing process.

\section{INTRODUCTION}

The blanking and piercing processes, in which a metallic sheet is placed between a die and a blankholder followed by the cut with the action of a punch moving downward, are the most widely used cutting techniques in the production of a variety of parts ranging, from electronics at the micrometre scale to components made of steels at the millimetre level. The quality of the products depends on many factors, including the design and material properties of the punch, cutting conditions, and tool wear. To avoid wear, it is important to reduce the stress on the punch by ensuring that it works for a long period without interruption as it is exposed to high dynamic loads and contact temperatures leading to high friction during the process. In the literature, different studies have been performed related to this. For instance, the effects of the punch-die clearance on punch life and edge quality have been investigated. Widenmann et al. [1] showed that the shear zone increased, while rollover and fracture zone decreased with decreasing punch-die clearance. Subramonian et al. [2] developed a method for the selection of the geometry-dependent optimum or best punch-die clearance for a significantly longer tool life. Few studies have focused on the effects of tool geometry. For instance, Singh et al. [3] investigated its effects on the blanking force and deformation of the punch in terms of the accuracy of the manufactured samples. This study showed that the punches with balanced convex and concave shear had the minimum radial deformations and the former showed the best performance in terms of the rigidity characteristics as the stress on the tool was reduced, and a thicker or more resistant workpiece could be punched. The research in [4] showed that both small rounded edge and slight clearance were essential for an improved quality of the finished product. In line with this, Song and Choi [5] demonstrated that the maximum blanking force could be reduced with a smaller tool edge radius and an increased thermal effect. Wang and Masood [6] investigated the performance of different punch edge profiles, such as standard circular, high elliptical and flat elliptical shapes. The combination of the first two was found to be more advantageous in minimizing wear. In another study, it was observed that the die edge radius had a relatively limited effect on the blanking force when compared to the case of changing the punch edge radius [7]. Engin and Eyercioglu [8] compared different cases in the blanking process (i.e., 
different ratios of workpiece thickness to die diameter under various clearance values) experimentally and numerically. The ideal values for each of these parameters were identified. In the present study, firstly, a novel punch with a special geometry, where a hemispherical ball was placed at the centre of its flat face, was proposed. The underlying idea was that since its spherical part contacted the central region of the workpiece at the initial stage, the tensile stresses evolved in the region to be cut make the cutting process smoother. To analyse it, a $2 \mathrm{D}$ axisymmetric finite element (FE) model was developed using the commercially available ABAQUS/Explicit. Such numerical models are beneficial in the choice of the process parameters; otherwise, a large number of expensive tests are required to attain them empirically through an iterative procedure [9]. The Johnson-Cook material model, with its complementary damage model, was used to model the behaviour of the workpiece material, where the crack propagation was simulated using the element deletion method.

Other ways to circumvent the tool wear also exist. For instance, different lubricants and tool materials are used. While the former has the disadvantage of environmentally hazardous ingredients and is not preferred due to subsequent cleaning requirements, the latter is not always an optimum choice due to high costs. Therefore, less expensive tools with higher wear resistance are desired. In recent decades, physical vapour deposition (PVD) and chemical vapour deposition (CVD) coatings have been increasingly used to protect and enhance the lifetime of cutting tools. Good adhesion to the base material to withstand high loads and shearing forces without chipping or peeling, high toughness and low friction against workpiece material are required for these tools [10] and [11]. Klocke and Raedt [12] tested different PVD coatings for the fine blanking process. Strong adhesion of the coating to the substrate and a high thermal conductivity were identified as critical properties to resist the imposed tribological loads. The type of coatings was studied in the literature extensively.

For instance, studies in [10] and [13] demonstrated that the traditional hard coatings such as $\mathrm{TiN}$, TiC and $\mathrm{CrN}$ could not always meet the blanking tool requirements as they cannot withstand high loads and shearing forces without peeling or chipping. In other studies [14] and [15], it was shown that the wear volume was lower for an $\mathrm{AlCrN}$ coated punch than a TiAlN one. The study of Bressan et al. [16] revealed that the TiAlN coating was superior to the TiCN for electric steel sheets. Recently, Yan et al. [17] studied the performance of AlTiN-coated oblique guillotine tools for the shearing of electrical steel sheets. It was found that the shear force dropped by $14.7 \%$ and the quality of fractured surfaces was significantly improved when compared to those sheared using the uncoated tool.

Diamond is the hardest material known; this property gives it superior properties for cutting any other material. Polycrystalline diamond compact (PDC) cutters are widely used in oil and gas drilling operations [18]. Their superior abrasion resistance is the main contributor to their excellent drilling efficiency. These cutters are composed of a layer of polycrystalline diamond bonded in-situ on a tungsten carbide substrate. The bonding is applied at high pressure through a high-temperature sintering process. To the best of the authors' knowledge, PDC cutters have not been used in the blanking process yet. In the second part of this study, for an improved shearing process, its performance and those of tools with different coatings, including TiN, CrN, TiSiN, $\mathrm{AlCrN}$, and AlTiN, were compared and contrasted. In particular, the initial period of wear was investigated for all the above-mentioned tools.

This paper continues as follows: a description of the materials used and details about the experimental study are given in Section 2. Section 3 describes first the developed finite-element model, then the theoretical description of the material model used in the simulations is given. In Section 4, the validation of the developed numerical model against experimental data is presented, followed by numerical predictions and wear analyses of the tools with different coatings and PDC cutter. The paper ends with some concluding remarks in Section 5.

\section{EXPERIMENTAL}

As the workpiece material, $2 \mathrm{~mm}$ thick low carbon hot-rolled ASTM A36 steels plates were used. This material is relatively ductile and can elongate up to $20 \%$ of its original length under tensile testing. Its physical and mechanical properties is given in Section 2 (for more details, see [19]). The punch used in the blanking experiments was made of DIN 1.2379 cold work tool steel (X155CrVMo 12-1). Its content is given in Table 1. A novel punch with a hemispherical ball at the centre of its flat face used in the experiment is shown in Fig. 1a. It was produced using the turning and grinding operations.

Wear occurs on the side of the punch when it passes and retracts through a metal. Due to the deflection of the sheet occurring during the punching, 
a)

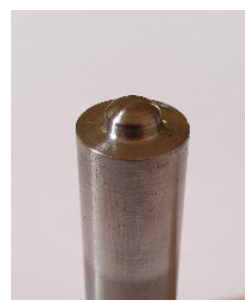

b)

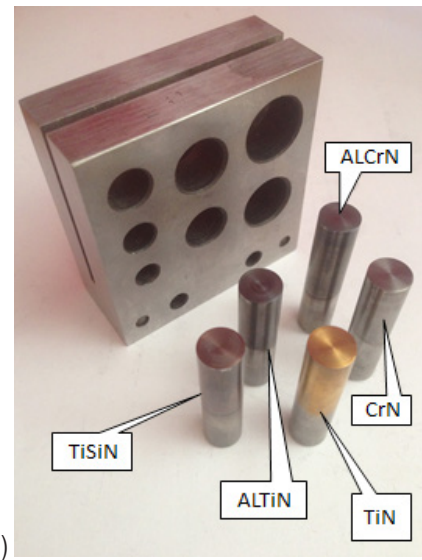

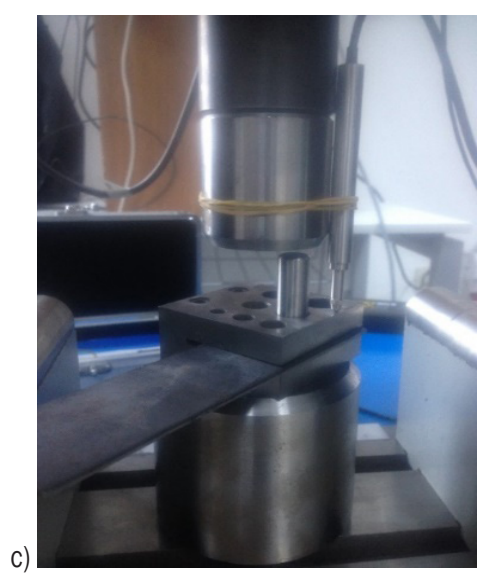

c)

ce, b) die set-up with coated tools, and c) experimental set-up for the blanking process the hole is distorted in the course of retraction of the tool, which causes the metal surroundings in the hole to scrape against the side of the punch leading to abrasion and wear. Coatings simultaneously increase the surface hardness and decrease the frictional forces allowing the punch to operate efficiently; ultimately, the lifetime of the tool is extended. In this study, five commercial PVD coatings were deposited on the substrate tool material using an industrial Hauzer rapid-coating-system (HCS) deposition machine equipped with a bucket plasma source [20]. The coatings are titanium nitride (TiN), chromium nitride $(\mathrm{CrN})$, titanium silicon nitride (TiSiN), aluminium chromium nitride $(\mathrm{AlCrN})$ and aluminium titanium nitride (AlTiN) (see Fig. 1b); $4 \mu \mathrm{m}$ thickness coatings were deposited at a substrate temperature of $500{ }^{\circ} \mathrm{C}$.

Table 1. Chemical composition (wt.,\%) of steel tool

\begin{tabular}{cccccc}
\hline $\mathrm{C}$ & $\mathrm{Si}$ & $\mathrm{Mn}$ & $\mathrm{Cr}$ & $\mathrm{Mo}$ & $\mathrm{V}$ \\
\hline 1.55 & 0.30 & 0.25 & 12.0 & 0.70 & 1.0 \\
\hline
\end{tabular}

Table 2. Tooling dimensions

\begin{tabular}{ll}
\hline Punch diameter & $12.6 \mathrm{~mm}$ \\
\hline Punch corner radius & $0.01 \mathrm{~mm}$ \\
\hline Punch holder clearance & $0.04 \mathrm{~mm}$ \\
\hline Punch die clearance & $0.04 \mathrm{~mm}$ \\
\hline
\end{tabular}

The shearing tests were carried out using the test set-up, and the MTS Series 810 hydraulic tensile machine with a $100 \mathrm{kN}$ load cell, as shown in Figs. $1 \mathrm{~b}$ and c. The cross-head velocity of $1.67 \mathrm{~mm} / \mathrm{s}$ was used. Each test was carried out three times, and the result of the one close to the average was presented in Section 3. The details of the tooling used in this study are shown in Table 2. Scanning electron microscope
(SEM), (Zeiss EVO-40 SEM microscope) was used to observe the microstructures on the worn surfaces of the punch.

\section{NUMERICAL MODELLING}

In this section, the numerical methodology used in the simulations is presented. Analyses of the tests were performed using ABAQUS/Explicit FE software. Fig. 2 shows the dimensions of the punch with a hemispherical ball $\left(R_{0}=3.39 \mathrm{~mm}\right)$ and the developed two-dimensional FE model of the process. An axisymmetric model was considered to reduce computational resource usage. Linear 4-node elements were used to discretize the sheet material. An enhanced stiffness-based hourglass and distortion control were employed to suppress spurious energy modes. A mesh convergence study was conducted using a refined mesh in the shearing band, the zone between the punch corner radius and the die corner radius, with element sizes ranging between $0.01 \mathrm{~mm}$ to $0.1 \mathrm{~mm}$ (an aspect ratio of around 1). Convergence was obtained in terms of the obtained force-displacement curve for the various meshes being less than $5 \%$. A mesh with an element size of $0.03 \mathrm{~mm}$ and a coarser mesh in the areas not subjected to high-stress levels was used. The tooling dimensions are identical to those explained in Section 2. Temperature rise and heat conduction within the sheet material were taken into account.

The interfaces between the sheet material and the tools were modelled using the general contact algorithm of the ABAQUS/Explicit [21]. This algorithm accounts for normal contact, with its tangential component simulated by assuming a friction coefficient of 0.02 . This value was selected based on 
the work presented in [22]. The punch, the blankholder and the die were considered as rigid bodies, and they were modelled as rigid analytical surfaces [8] and [22], for which the punch was allowed to move only in the z-direction, and the others were fixed in all degrees of freedom to mimic the experiments.

a)

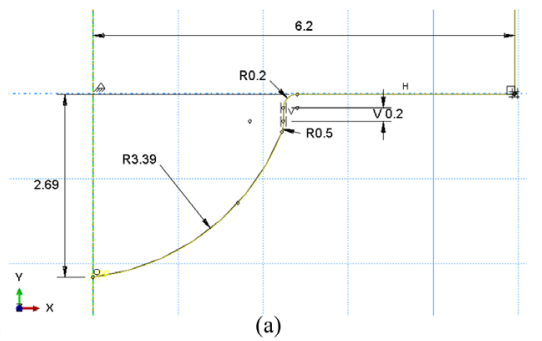

(a)

Punch B

(novel punch)

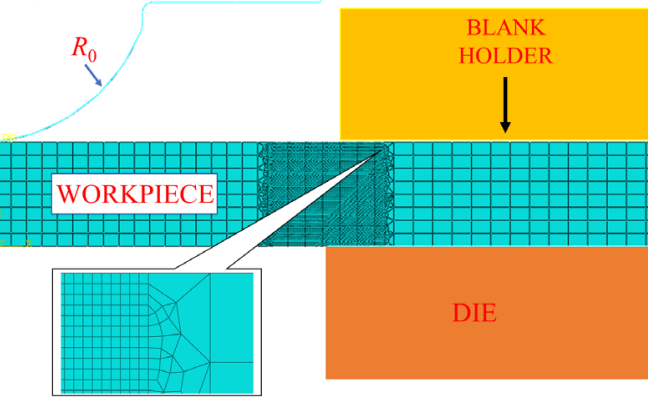

Fig. 2. a) Geometric description of the punch with the hemispherical ball (all dimensions are in $\mathrm{mm}$ ), and b) 2D axisymmetric FE model of the workpiece material in the shearing process

The material behaviour of the sheet material is modelled using the Johnson-Cook (JC) constitutive model with its complementary damage model. In the next, details about each are given.

The JC phenomenological constitutive model considers the separated effects of strain hardening, strain-rate (viscosity) and thermal softening [21]. The following equation represents it as:

$$
\bar{\sigma}_{f}=\left[\mathrm{A}+\mathrm{B}\left(\bar{\varepsilon}_{p}\right)^{\mathrm{n}}\right] \cdot\left[1+\mathrm{C} \ln \frac{\dot{\bar{\varepsilon}}}{\dot{\bar{\varepsilon}}_{0}}\right] \cdot\left[1-\left(\frac{T-\mathrm{T}_{0}}{\mathrm{~T}_{\mathrm{m}}-\mathrm{T}_{0}}\right)^{\mathrm{m}}\right],
$$

where $\bar{\sigma}_{f}$ is the equivalent plastic stress, $\bar{\varepsilon}_{p}$ is the equivalent plastic strain, $\dot{\bar{\varepsilon}}$ is the equivalent plastic strain rate, $\dot{\bar{\varepsilon}}_{0}$ is the reference equivalent plastic strain rate, $T$ is the temperature, $\mathrm{T}_{0}$ and $\mathrm{T}_{\mathrm{m}}$ are the room and melting temperature of the workpiece material, respectively. A, B, C, $\mathrm{m}$ and $\mathrm{n}$ are material parameters determined based on the flow stress data obtained from mechanical tests. The JC constitutive model parameters, the physical and mechanical properties of Steel A36 used to simulate its mechanical the behaviour in the blanking process are specified in Tables 3 and 4, respectively.

To model the process more realistically, i.e., to simulate the separation in the workpiece during cutting, the progressive damage model was used. It consists of two parts: damage initiation and its evolution. For the former, the JC damage model [21] was used. It was adopted in conjunction with the JC constitutive model. It is an empirical model represented by the following equation:

$$
\begin{aligned}
\bar{\varepsilon}_{f}^{p l}= & {\left[\mathrm{D}_{1}+\mathrm{D}_{2} \exp \left(\mathrm{D}_{3} \frac{\sigma_{m}}{\sigma_{e q}}\right)\right] \cdot\left[1+\mathrm{D}_{4} \ln \frac{\dot{\bar{\varepsilon}}}{\dot{\bar{\varepsilon}}_{0}}\right] . } \\
& {\left[1+\mathrm{D}_{5} \frac{T-\mathrm{T}_{0}}{\mathrm{~T}_{\mathrm{m}}-\mathrm{T}_{0}}\right], }
\end{aligned}
$$

where $\bar{\varepsilon}_{f}^{p l}$ is the failure strain, $\sigma_{m} / \sigma_{e q}$ is the stress triaxiality $(\eta)$ as the ratio of mean stress to the von Mises effective stress, $\dot{\bar{\varepsilon}} / \dot{\bar{\varepsilon}}_{0}$ is the dimensionless ratio of strain rates and $\mathrm{D}_{1}$ to $\mathrm{D}_{5}$ are material constants.

\begin{tabular}{|c|c|c|c|}
\hline $\mathrm{A}[\mathrm{MPa}]$ & 286 & $\mathrm{~m}$ & 0.917 \\
\hline $\mathrm{B}[\mathrm{MPa}]$ & 500 & $\mathrm{~T}_{\mathrm{m}}\left[{ }^{\circ} \mathrm{C}\right]$ & 1430 \\
\hline $\mathrm{n}$ & 0.228 & $\mathrm{~T}_{0}\left[{ }^{\circ} \mathrm{C}\right]$ & 25 \\
\hline $\mathrm{C}$ & 0.017 & $\dot{\bar{\varepsilon}}_{0}\left[\mathrm{~s}^{-1}\right]$ & 1 \\
\hline
\end{tabular}

Table 3. Johnson-Cook constitutive model parameters of Steel A36 [23]

Table 4. Physical and mechanical properties of Steel A36 [23] and [24]

\begin{tabular}{lc}
\hline Density $\left[\mathrm{kg} / \mathrm{m}^{3}\right]$ & 7850 \\
\hline Young's modulus $[\mathrm{MPa}]$ & 200000 \\
\hline Poisson ratio & 0.26 \\
\hline Specific heat fraction $\left[\mathrm{J} /\left(\mathrm{kg}^{\circ} \mathrm{C}\right)\right]$ & 486 \\
\hline Inelastic heat fraction & 0.9 \\
\hline Thermal conductivity $\left[\mathrm{W} /\left(\mathrm{m}^{\circ} \mathrm{C}\right)\right]$ & 52 \\
\hline Expansion coefficient $\left[1 /{ }^{\circ} \mathrm{C}\right]$ & $1.2 \mathrm{e}-5$ \\
\hline
\end{tabular}

As the simulations were performed quasistatically [25], the strain-rate and temperature effects were not significant; thus, the second and third terms in the above equation did not influence $\bar{\varepsilon}_{f}^{p l}$ substantially. Damage initiation occurs if the following condition is satisfied.

$$
\int \frac{d \bar{\varepsilon}^{p l}}{\varepsilon_{f}^{p l}(\eta)}=1
$$


In this equation, $\bar{\varepsilon}^{p l}$ is the equivalent plastic strain value. The constants of this fracture model used in the simulations are presented in Table 5.

Table 5. Johnson-Cook fracture model parameters of Steel A36 [18]

\begin{tabular}{cccc}
\hline $\mathrm{D}_{1}$ & $\mathrm{D}_{2}$ & $\mathrm{D}_{3}$ & $\mathrm{D}_{4}$ \\
\hline 0.403 & 1.107 & 0.1 & 0.00961 \\
\hline $\mathrm{D}_{5}$ & $\mathrm{~T}_{\mathrm{m}}\left[{ }^{\circ} \mathrm{C}\right]$ & $\mathrm{T}_{0}\left[{ }^{\circ} \mathrm{C}\right]$ & $\dot{\bar{\varepsilon}}_{0}\left[\mathrm{~s}^{-1}\right]$ \\
\hline 0 & 1430 & 25 & 1 \\
\hline
\end{tabular}

The evolution of the damage following its initiation describes the progressive damage of the material, which is implemented by displacement type linear softening law, with which the evolution of the damage variable $(d)$ is explained through the following equation:

$$
\dot{d}=\frac{L_{e} \cdot \dot{\bar{\varepsilon}}^{p l}}{\bar{u}_{f}^{p l}}=\frac{\dot{\bar{u}}^{p l}}{\bar{u}_{f}^{p l}},
$$

where $L_{e}$ is the characteristic length of the element, $\dot{\bar{\varepsilon}}^{p l}$ is the equivalent plastic strain rate and $\bar{u}_{f}^{p l}$ is the effective plastic displacement at failure. When the effective plastic displacement $\left(\bar{u}^{p l}\right)$ reaches $\bar{u}_{f}^{p l}$, the material stiffness is fully degraded $(d=1)$, i.e., the complete damaged occurs, then the element is removed from the mesh. In the simulations, $\bar{u}_{f}^{p l}$ was set to $0.1 \mathrm{~mm}$.

\section{RESULTS AND DISCUSSION}

In this section, the shearing process was investigated extensively for different punch characteristics, including different geometries of the novel punch, coating type and type of the tool used.

\subsection{Validation of the FE Model}

In this section, the developed FE model was validated with the experiments performed (to examine its accuracy) for the regular punch (punch A, denoted as "Flat" henceforth) and the novel punch with a hemispherical ball at its centre (punch $\mathrm{B}$, denoted as " $R_{0}$ "). It should be mentioned that both tools were uncoated. In the simulations, the field parameters such as the reaction force and displacement values were written for every increment as data for the reference point of the punch. Experimentally and numerically obtained force-displacement $(P-\delta)$ curves for both punches are presented in Fig. 3. A good agreement between the curves was achieved; this validated the developed model, i.e., the process was simulated successfully. For the first punch, it was observed that the force increased with the indentation of the punch until the crack initiated on the sheet material followed by a decrease in the force value with the propagation of the crack inside the sheet. For the novel punch, the force increased with the indentation of the punch initially with a smaller slope compared to that of the

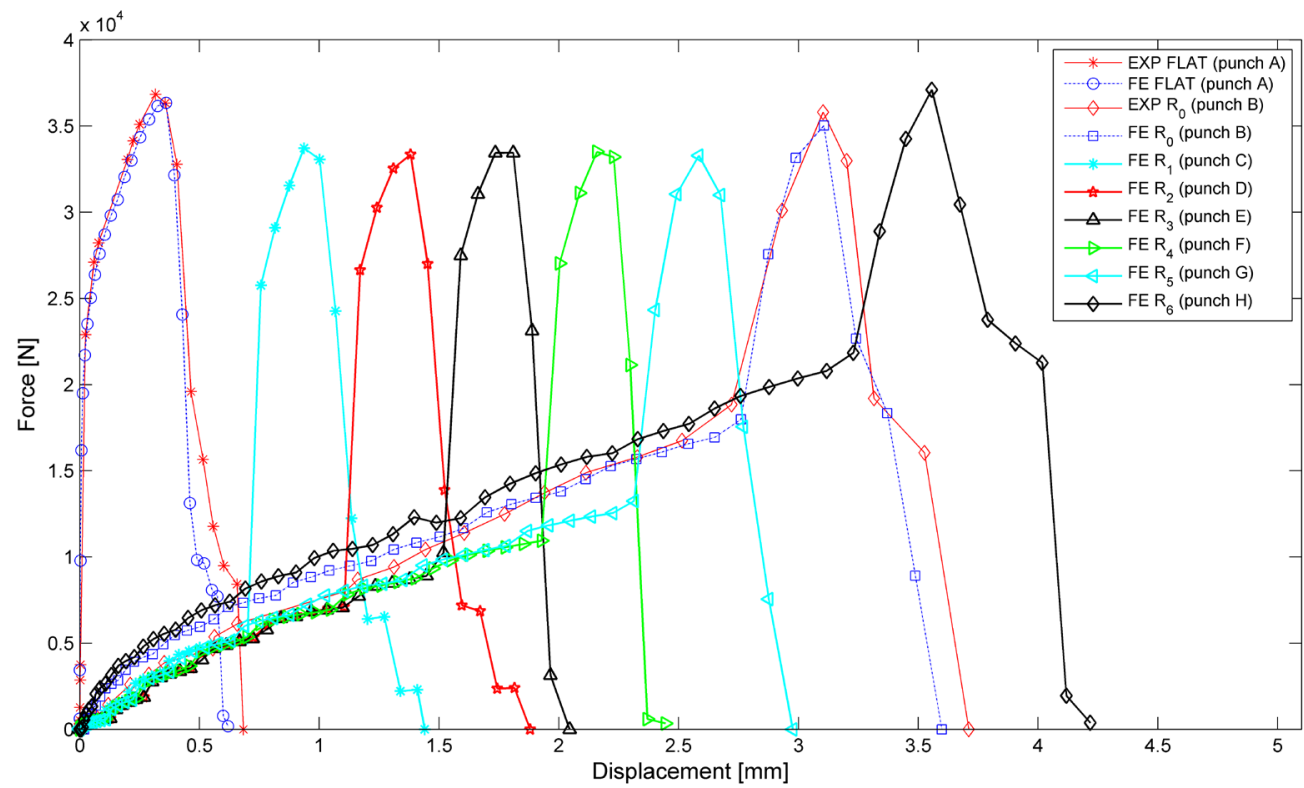

Fig. 3. Experimentally and numerically obtained load-displacement curves for different hemispherical radii at the centre of the flat face of the punch 
punch A due to the contact of the hemispherical part of the punch with the workpiece material. This was followed by a change in the slope of the $P-\delta$ curve, where a steeper force increase was attained with the corners of the punch started contacting the workpiece material. The characteristic of the $P-\delta$ curve in this second stage, including its decrease (after the peak load was achieved) was similar to that explained for the conventional punch.

\subsection{Effect of the Geometry of the Novel Punch}

The influence of the radius of the hemispherical ball at the centre of its flat face on the blanking force was investigated. For that purpose, its various values, namely, $R_{1}=1.4 \mathrm{~mm}$ (punch C), $R_{2}=1.8 \mathrm{~mm}$ (punch $\mathrm{D}), R_{3}=2.2 \mathrm{~mm}$ (punch E), $R_{4}=2.6 \mathrm{~mm}$ (punch F), $R_{5}=3.0 \mathrm{~mm}$ (punch $\mathrm{G}$ ) and $R_{6}=3.8 \mathrm{~mm}$ (punch $\mathrm{H}$ ), were considered in the simulations. They were chosen by taking the punch used in the experiment $\left(R_{0}=\right.$ $3.39 \mathrm{~mm}$ ) as a reference, and a constant interval of $0.4 \mathrm{~mm}$ was considered for the radius between two neighbouring tool geometries. The respective $P-\delta$ curves are presented in Fig. 3. It was observed that with an increase in $R$, the workpiece material was in contact with the hemispherical ball of the punch for larger displacement values when compared its contact with the corners of the punch. Consequently, the maximum force in the first stage became closer to the overall maximum cutting force. However, the change in the peak force remained limited for different punch geometries studied here. To obtain a realistic insight into the problem, instead of considering only the punch load, the amount of energy absorbed (EA) as the area under the force-displacement curve was also analysed for all the cases. The trapezoidal rule available inside the Microsoft Excel software was used to estimate the area under the curve as a series of trapezoids. Table 6 presents the respective values for the first and second (shearing) stages as well as their sum as the overall absorbed energy obtained from simulations. When a hemispherical ball was adapted to the punch, with an increase in the radius of the ball, the EA in the first stage and total EA increased, whereas the EA of the shearing stage showed a valleyshaped behaviour where it first dropped and later increased. The maximum blanking force also showed a similar feature where the maximum cutting force dropped first from $36.35 \mathrm{kN}$ to $33.45 \mathrm{kN}$, followed by an increase to $37.11 \mathrm{kN}$ (Table 6). Since the wear on the tool surface during the process mostly occurs at the corners, a smaller amount of energy absorbed in the shearing stage and a smaller $F_{\text {max }}$ implied longer tool life. Here, the punches $\mathrm{E}$ and $\mathrm{F}$ with radius values of $2.2 \mathrm{~mm}$ and $2.6 \mathrm{~mm}$, respectively were found to be the optimum tool designs based on these two criteria.

In the shearing process, the cutting force starts to decrease with the initiation of the crack and in the final section the force is dominated by the friction between the sheet material and the shell surface of the punch. The slope change in the $P-\boldsymbol{\delta}$ curve (after the maximum force was obtained) in Fig. 3 indeed separated these two sections. It was observed that the frictional resistance was insignificant for the punches $\mathrm{E}$ and $\mathrm{F}$, which assured them as good alternatives to the conventional punch.

The surface quality of the products obtained with different punches should also be analysed along with the cutting force and energy values [8]. Fig. 4 presents the respective deformed shapes after the cutting process with the lengths of rollover, shear and fracture zones. First, it was observed that the rollover zone reached its smallest values, $0.125 \mathrm{~mm}$ and $0.135 \mathrm{~mm}$, for punches $\mathrm{E}$ and $\mathrm{F}$, whereas this length was much larger for punches B, G and $\mathrm{H}$. In contrast, the shear zone reached its maximum value for the punches $\mathrm{E}$

Table 6. Numerically obtained maximum shearing force and energy absorption values in the cutting process for the different hemispherical radius at the centre of the flat face of the punch

\begin{tabular}{lcccc}
\hline $\begin{array}{l}\text { Radius of } \\
\text { hemispherical part }\end{array}$ & $\begin{array}{c}\text { Maximum shearing force } \\
{[\mathrm{N}]}\end{array}$ & $\begin{array}{c}\text { Energy absorption - first stage } \\
{[\mathrm{J}]}\end{array}$ & $\begin{array}{c}\text { Energy absorption - shearing } \\
{[\mathrm{J}]}\end{array}$ & $\begin{array}{c}\text { Total energy absorption } \\
{[\mathrm{J}]}\end{array}$ \\
\hline Flat (punch $\mathrm{A})$ & 36348 & - & 14961 & 14961 \\
\hline$R_{1}$ (punch $\mathrm{C}$ ) & 33718 & 2272 & 13334 & 15606 \\
\hline$R_{2}$ (punch $\left.\mathrm{D}\right)$ & 33552 & 4586 & 13040 & 17626 \\
\hline$R_{3}$ (punch $\left.\mathrm{E}\right)$ & 33508 & 8056 & 11657 & 19713 \\
\hline$R_{4}$ (punch $\left.\mathrm{F}\right)$ & 33451 & 12503 & 11206 & 23709 \\
\hline$R_{5}$ (punch $\left.\mathrm{G}\right)$ & 33521 & 17757 & 14045 & 31802 \\
\hline$R_{0}$ (punch $\left.\mathrm{B}\right)$ & 35029 & 29052 & 18718 & 47777 \\
\hline$R_{6}$ (punch $\left.\mathrm{H}\right)$ & 37107 & 41278 & 23609 & 64887 \\
\hline
\end{tabular}




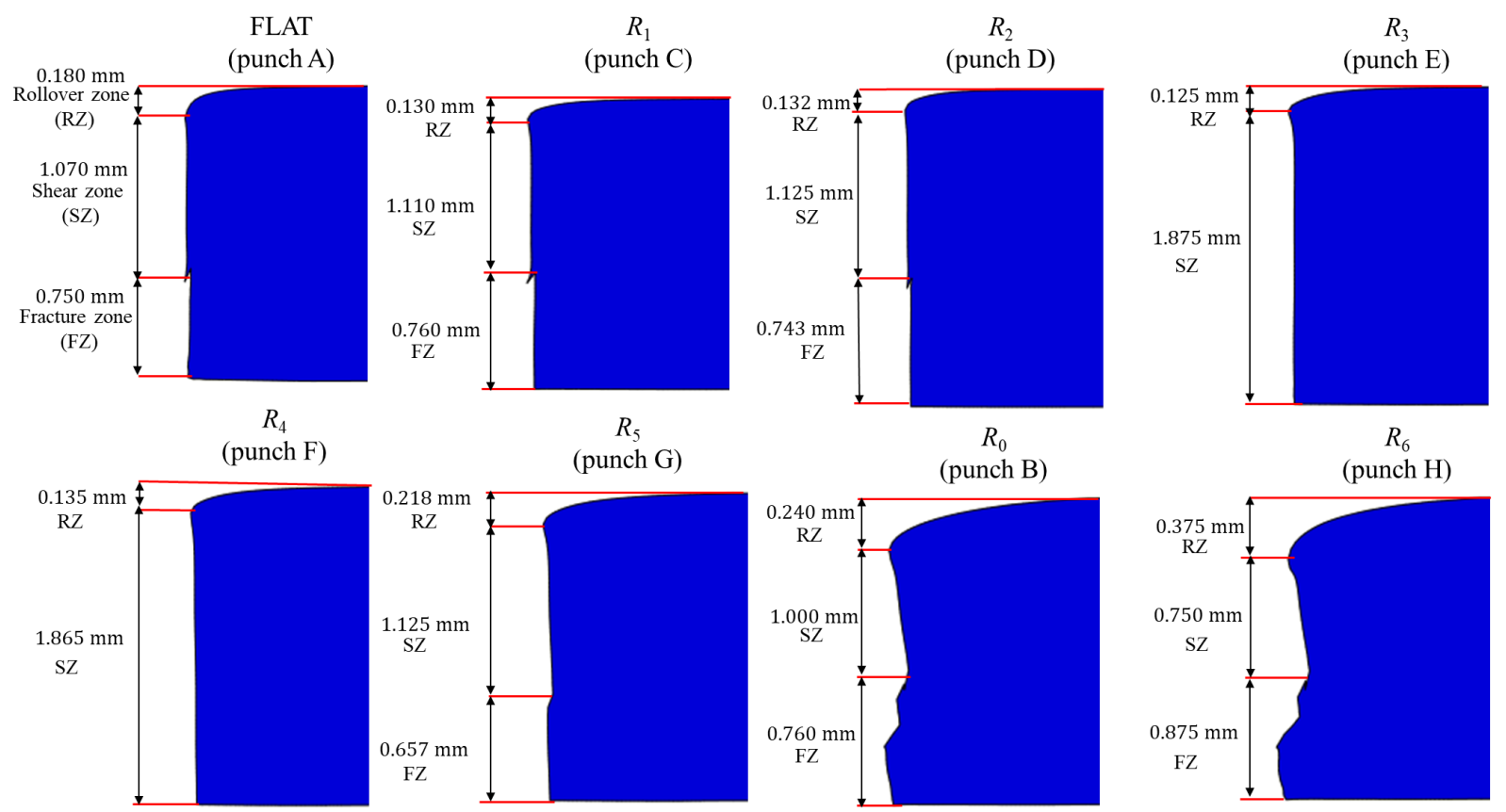

Fig. 4. Deformed shapes of the workpiece material including the lengths of rollover, shear and fracture zones when it was cut with different punches

and $\mathrm{F}$, where no fracture zone was observed. In the shearing process, an improved part edge quality is quantified by a decrease in the fracture and rollover zone lengths and an increase in the shear zone length. Consequently, the novel tool presented here with its $R$-value ranging from $2.2 \mathrm{~mm}$ (represented by punch E) to $2.6 \mathrm{~mm}$ (punch $\mathrm{F}$ ) requiring minimum shearing energy (as shown above) demonstrated also a better cutting performance in terms of the surface finish.

In contrast, the surface quality obtained using a regular punch was compared with those having too large a radius of the hemispherical ball, such as punches $\mathrm{B}$ and $\mathrm{H}$. The former one was observed to be better due to shorter rollover and fracture zone lengths. These two tools with also absorbed more energy in the shearing process values of $18718 \mathrm{~J}$ and $23609 \mathrm{~J}$ with respect to that of the conventional punch A with a value of $14961 \mathrm{~J}$. In contrast, punches C and $\mathrm{D}$ with relatively smaller radii of the hemispherical part did not show promising performance when compared to the conventional punch as the values of the parameters for them (lengths of different zones of the sheared surface, amount of energy absorbed) were very close to each other. It was therefore concluded that the novel punch could be more effective in the cutting process (with respect to a conventional punch) for a certain range of the radius of the hemispherical ball at the centre of its end.
It is noteworthy that as the hemispherical part of the punch deforms the punched out piece of the sheet material; this part may not be used in service. Therefore, using such a geometrical configuration for the punch is not appropriate in the blanking process, but can be used in the punching process, where the punched out piece is scrap.

\subsection{Effect of Coating and Punch Type}

In the last part of the present paper, the cutting performance of uncoated punch and TiN, CrN, TiSiN, $\mathrm{AlCrN}$ and AlTiN coated punches were investigated. Since the coating of a punch with a hemispherical ball at the centre of its flat face was not straightforward in terms of coating it identically all over the surface, it was not considered in this part; instead, the regular punch was coated. The wear on the tools after 1000 strokes were compared. All the tests were carried out under dry cutting conditions without using any lubrication. SEM was used to observe the microstructures of cross-sections and worn-out surfaces. Fig. 5 presents the respective micrographs. The uncoated punch shows significant flank wear; thus, its wear volume is significantly higher when compared to the other punches, as expected. The coating layer was damaged substantially for TiN and $\mathrm{CrN}$ coatings; in particular, there was edge wear 


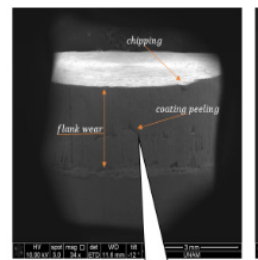

(A)

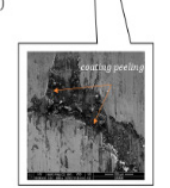

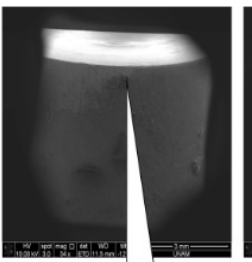

(B)

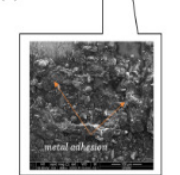

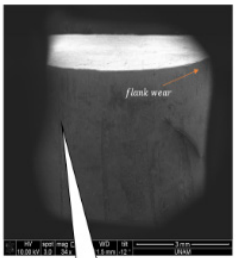

(c)

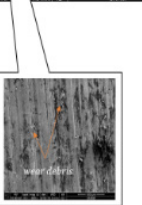

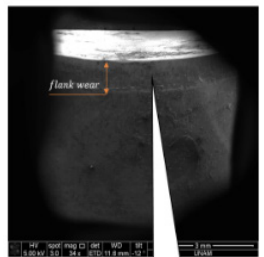

(D)

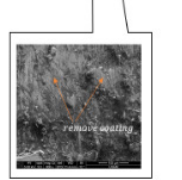

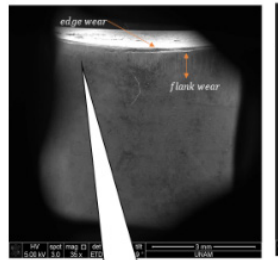

(E)

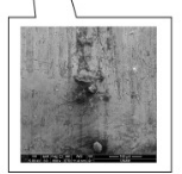

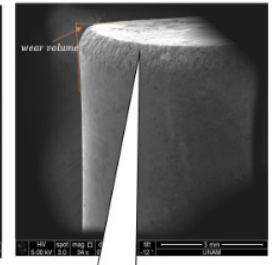

(F)

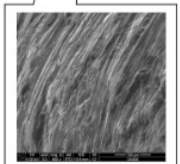

Fig. 5. SEM micrograph of the cross-section of the cutting edge of (A) TiSiN, (B) AICrN, (C) AITiN, (D) TiN, (E) CrN coated punches and $(F)$ uncoated punch after 1000 strokes

for the latter one. It might be useful to evaluate the performance of the coatings in connection with their mechanical and tribological properties. Hardness values of coated tools and their friction coefficient values are given in Table 7. As shown, TiN and $\mathrm{CrN}$ coatings have the lowest hardness values with values of $27.4 \mathrm{GPa}$ and $22.5 \mathrm{GPa}$, respectively, when compared to others. Significant wear for TiN and $\mathrm{CrN}$ coatings may be attributed to their lower hardness.

In contrast, although the TiSiN-coated punch has one of the highest hardness and lowest friction coefficients (see Table 7), peelings of the coating material, chipping and flank wear were observed on different regions of the surface of the punch. Therefore, it is not superior to the AlTiN and $\mathrm{AlCrN}$ coated tools. That can be explained by the fact that these two coated tools may have a larger adhesion strength and better thermal and chemical stability [11]. While the flank wear and wear debris were observed on the edge and surface of the AlTiN coated punch, no severe wear was caught on that of the AlCrN coated punch. That proved the better performance of the latter coating. Parallel observations were made in the literature.

Table 7. Properties of the hard coatings studied [20]

\begin{tabular}{ccc}
\hline Coating material & Micro hardness HV 0.05 [GPa] & Friction coefficient \\
\hline TiN & 27.4 & 0.50 \\
\hline CrN & 22.5 & 0.55 \\
\hline TiSiN & 34.3 & 0.40 \\
\hline AICrN & 29.4 & 0.55 \\
\hline AITiN & 34.3 & 0.60 \\
\hline
\end{tabular}

The wear volume was lower and increased more steadily for $\mathrm{AlCrN}$ coated punch when compared to that of TiAlN coated one [14]. Erdogan and Altas [26] studied the micro abrasion behaviours of TiN,
TiAlN, TiAlN/TiSiN and AlCrN coatings using F800 and $\mathrm{F} 1200 \mathrm{SiC}$ particles under three loads $(0.5 \mathrm{~N}$, $1 \mathrm{~N}$ and $2 \mathrm{~N}$ ) for two cycles (140 and 420). Similar to our finding, the AlCrN and TiN coatings had the highest and lowest micro-abrasion resistance among the four coatings, respectively. In another study, it was reported that the tool life of $\mathrm{AlCrN}$ coating was 2.5 and 5 times longer than those of TiN-coated and uncoated punches, respectively [15]. Fig. 6 presents the SEM micrograph of the top edge of the PDC cutter after 1000 strokes. It is observed that the flank wear is negligibly small; hence, it may be a good alternative for the shearing process. An important advantage of a PDC cutter is when the wear develops on the tool, its life can be extended using a grinding process, which is not the case for a coated punch.
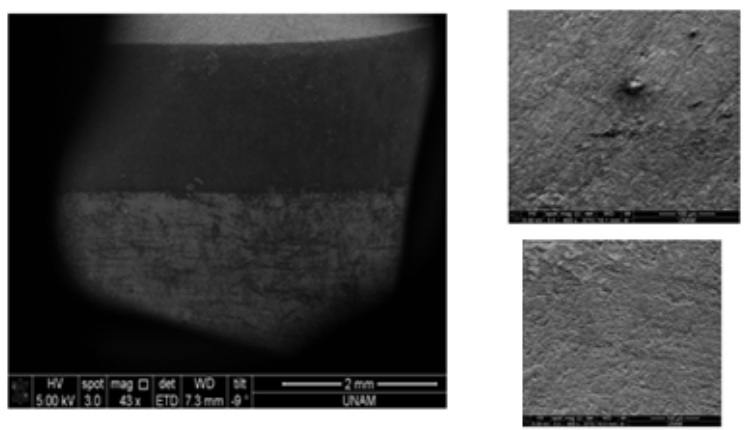

Fig. 6. SEM micrograph of the top edge of the PDC cutter after 1000 strokes

\section{CONCLUSION}

This study focused on the investigation of the effect of tool geometry, tool type and coating type on tool wear in the shearing process. To achieve this, combined experimental and 2D FE simulation studies were performed. The Johnson Cook constitutive model 
and its complementary damage model were used to simulate the behaviour of the sheet material.

From the study, the following observations and conclusions were made:

- The novel punch with a hemispherical ball on its flat surface with a radius of $2.2 \mathrm{~mm}$ to 2.6 $\mathrm{mm}$ was found to be the optimum tool geometry with absorbing less amount of energy, requiring smaller cutting force and better surface quality. Such punches could be used especially in the punching process, where the punched-out piece is scrap rather than in the blanking process. However, the punch with a too large radius of its hemispherical part demonstrated a worse performance when compared to a conventional punch.

- The wear volume at the punch edge is significantly larger for the uncoated one. AlTiN and AlCrN coated punches showed less flank wear when compared to the TiN and $\mathrm{CrN}$ coatings. Peelings of the coating material were observed for the TiSiN coated punch, even though it has one of the highest hardness and lowest friction coefficient. It was observed that there was no significant wear on the surface of the PDC cutter.

\section{ACKNOWLEDGEMENTS}

The authors would like to thank to Prof. Ferhat Kadioglu for providing the academic licenses for ABAQUS software.

\section{REFERENCES}

[1] Widenmann, R., Sartkulvanich, P., Altan, T. (2009). Finite element analysis on the effect of sheared edge quality in blanking upon hole expansion of advanced high strength steel. IDDRG International Conference.

[2] Subramonian, S., Altan, T., Ciocirlan, B., Campbell, C. (2013). Optimum selection of variable punch-die clearance to improve tool life in blanking non-symmetric shapes. International Journal of Machine Tools and Manufacture, vol. 75, p. 63-71, Dol:10.1016/j.jimachtools.2013.09.004.

[3] Singh, U.P., Streppel, A.H., Kals, H.J.J. (1992). Design study of the geometry of a punching/blanking tool. Journal of Materials Processing Technology, vol. 33, no. 4, p. 331-345, DOI:10.1016/0924-0136(92)90270-3.

[4] Mori, K., Abe, Y., Kidoma, Y., Kadarno, P. (2013). Slight clearance punching of ultra-high strength steel sheets using punch having small round edge. International Journal of Machine Tools and Manufacture, vol. 65, p. 41-46., DOl:10.1016/j.jijmachtools.2012.09.005.

[5] Song, S.H., Choi, W.C. (2016). FEM investigation on thermal effects on force in high-speed blanking of mild steel. International Journal of Precision Engineering and
Manufacturing, vol. 17 , no. 5, p. 631-635, Dol:10.1007/ s12541-016-0076-y.

[6] Wang, X.Z., Masood, S.H. (2011). Investigation of die radius arc profile on wear behaviour in sheet metal processing of advanced high strength steels. Materials \& Design, vol. 32, no. 3, p. 1118-1128, Dol:10.1016/j.matdes.2010.11.005.

[7] Song, S.H., Choi, W.C. (2015). FEM analysis on the influence of rounded tool edge on micro-blanking of thin foil with negative clearance. International Journal of Precision Engineering and Manufacturing, vol. 16, no. 6, p. 1101-1105, Dol:10.1007/ s12541-015-0142-x.

[8] Engin, K.E., Eyercioglu, O. (2017). The effect of the thicknessto-die diameter ratio on the sheet metal blanking process. Strojniški vestnik - Journal of Mechanical Engineering, vol. 63, no. 9, p. 501-509, D0I:10.5545/sv-jme.2016.4272.

[9] Bolka, Š., Slavič, J., Boltežar, M. (2015). Identification of out-ofplane material characteristics through sheet-metal blanking. Strojniški vestnik - Journal of Mechanical Engineering, vol. 61, no. 4, p. 217-226, D0l:10.5545/sv-jme.2014.2302.

[10] Voevodin, A.A., Schneider, J.M., Rebholz, C., Matthews, A. (1996). Multilayer composite ceramicmetal-DLC coatings for sliding wear applications. Tribology International, vol. 29, no. 7, p. 559-570, Dol:10.1016/0301-679X(95)00121-J.

[11] Zeng, X.T., Zhang, S., Muramatsu, T. (2000). Comparison of three advanced hard coatings for stamping applications. Surface and Coatings Technology, vol. 127, no. 1, p. 38-42, DOI:10.1016/S0257-8972(99)00668-4.

[12] Klocke, F., Raedt, H.-W. (2001). Formulation and testing of optimised coating properties with regard to tribological performance in cold forging and fine blanking applications. International Journal of Refractory Metals and Hard Materials, vol. 19, no. 4-6, p. 495-505, D0l:10.1016/S02634368(01)00029-4.

[13] Subramanian, C., Strafford, A.K. (1993). Review of multicomponent and multilayer coatings for tribological applications. Wear, vol. 165, no. 1, p. 85-95, Dol:10.1016/0043-1648(93)90376-W.

[14] Çöl, M., Kir, D., Erişir, E. (2013). Wear and blanking performance of AICrN PVD-coated punches. Materials Science, vol. 48, no. 4, p. 514-520, D0l:10.1007/s11003-013-9532-3.

[15] Wang, L., Nie, X., Housden, J., Spain, E., Jiang, J. C., Meletis, E. I., Matthews, A. (2008). Material transfer phenomena and failure mechanisms of a nanostructured $\mathrm{Cr}-\mathrm{Al}-\mathrm{N}$ coating in laboratory wear tests and an industrial punch tool application. Surface and Coatings Technology, vol. 203, no. 5-7, p. 816821, D0I:10.1016/j.surfcoat.2008.05.045.

[16] Bressan, J.D., Hesse, R., Silva Jr., E.M. (2001). Wear mechanisms of electrical steel sheets, hard metal and high speed steel pins coated with TiAIN and TiCN. Meccanica, vol. 36, no. 6, p. 683-690, Dol:10.1023/A:1016352904690.

[17] Yan, Q., Kuang, Z., Lu, J. (2018). Effect of AlTiN-coating oblique guillotine tools on their performance when shearing electrical steel sheets. The International Journal of Advanced Manufacturing Technology, vol. 99, no. 1-4, p. 819-831, D0I:10.1007/s00170-018-2475-y.

[18] Li, X.B., Summers, D.A., Rupert, G., Santi, P. (2001). Experimental investigation on the breakage of hard rock by the PDC cutters with combined action modes. Tunnelling and 
Underground Space Technology, vol. 16, no. 2, p. 107-114, DOI:10.1016/S0886-7798(01)00036-0.

[19] ASTM A36/A36M-14, Standard Specification for Carbon Structural Steel, ASTM International, West Conshohocken.

[20] Ionbond (2018). from https://www.ionbond.com/, accessed on 2018-07-20.

[21] ABAQUS. (2016). ABAQUS analysis user's manual. Version 2016: Dassault Systemes, Simulia Corporation.

[22] Husson, C., de Magalhaes Correia, J.P., Daridon, L., Ahzi, S. (2008). Finite element simulations of thin copper sheets blanking: Study of blanking parameters on sheared edge quality. Journal Materials Processing Technology, vol. 199, no. 1-3, p. 74-83, D0I:10.1016/j.jmatprotec.2007.08.034.

[23] Schwer, L. (2007). Optional strain-rate forms for the Johnson Cook constitutive model and the role of the parameter epsilon_0. 6th European LS_DYNA Users' Conference, p. 1-17.
[24] Seidt, J.D., Gilat, A., Klein, J.A., Leach, J.R. (2007). High strain rate, high temperature constitutive and failure models for EOD impact scenarios. Proceedings of the SEM Annual Conference \& Exposition on Experimental and Applied Mechanics, Society for Experimental Mechanics, p. 15.

[25] Demiral, M., Kadioglu, F. (2018). Failure behaviour of the adhesive layer and angle ply composite adherends in single lap joints: A numerical study. International Journal of Adhesion and Adhesives, vol. 87, p. 181-190, D0l:10.1016/j. ijadhadh.2018.10.

[26] Erdoğan, A., Altaş, E. (2019). Experimental study on microabrasion behavior of hard coatings: the role of load, sliding distance and abrasive particle size. Materials Research Express, vol. 6, no. 11, p. 116430, D0l:10.1088/2053-1591/ ab47ad. 